\title{
KUALITAS PENGELOLAAN RUANG PRAKTIK BUSANA SMK DI PROVINSI BALI UNTUK MENINGKATKAN PELAJARAN PROGRAM PRODUKTIF
}

\author{
Oleh \\ Made Diah Angendari \\ Jurusan Pendidikan Kesejahteraan Keluarga, FTK, UNDIKSHA
}

\begin{abstract}
ABSTRAK
Penelitian ini bertujuan untuk mendeskripsikan (1) kualitas perencanaan ruang praktik busana SMK di Provinsi Bali untuk meningkatkan pelajaran program produktif, (2) kualitas pengorganisasian ruang praktik busana SMK di Provinsi Bali untuk meningkatkan pelajaran program produktif , (3) kualitas pengawasan ruang praktik busana SMK di Provinsi Bali untuk meningkatkan pelajaran program produktif. Penelitian ini menggunakan rancangan penelitian deskriptif kuantitatif, dengan obyek semua SMK yang memiliki program Keahlian Tata Busana di Provinsi Bali yang berjumlah 6 SMK. Instrumen penelitian yang digunakan berupa dokumentasi dan lembar observasi. Data penelitian yang diperoleh kemudian dibandingkan dengan standar kualitas yang ditetapkan oleh Permendiknas no 40 tahun 2008 dan dianalisis statistik deskriptif untuk menentukan kategori kualitas yaitu, sangat kurang baik, kurang baik, cukup baik, baik, dan sangat baik.

Hasil penelitian menunjukkan bahwa: (1) Kualitas perencanaan ruang praktik busana Sekolah Menengah Kejuruan di Provinsi Bali adalah sangat baik. (2) Kualitas pengorganisasian ruang praktik busana Sekolah Menengah Kejuruan di Provinsi Bali adalah sangat baik. (3) Kualitas pengawasan ruang praktik busana Sekolah Menengah Kejuruan di Provinsi Bali adalah sangat baik.
\end{abstract}

Kata-kata Kunci: Pengelolaan, Ruang Praktik Busana, Provinsi Bali

\begin{abstract}
This study aimed to describe (1) the quality of vocational clothing spatial planning practices in Bali province to increase productive learning programs, (2) the quality of the organization 's office in the province of Bali fashion vocational learning programs to enhance the productive, (3) quality of fashion vocational practice space surveillance Bali province to increase productive lesson program.

This study used a descriptive quantitative research design, with the object of all vocational programs that have dressmaking skills in the province of Bali, amounting to $6 \mathrm{SMK}$. The research instrument used in the form of documentation and observation sheets. The research data obtained were then compared with the quality standards set by the Ministerial Regulation No. 40 of 2008 and descriptive statistics were analyzed to determine the categories of quality, namely, very poor, poor, pretty good, good, and excellent. The results showed that: (1) The quality of spatial
\end{abstract}


planning vocational school fashion practice in the Province of Bali is very good. (2) Quality of organizing space vocational school fashion practice in the Province of Bali is very good. (3) Quality control area vocational school fashion practice in the Province of Bali is very good.

Keywords : Management, Practice Space Clothing, Bali Province

\section{PENDAHULUAN}

Sekolah Menengah Kejuruan merupakan salah satu lembaga pendidikan yang bertanggung jawab untuk menciptakan sumber daya manusia yang memiliki kemampuan, keterampilan dan keahlian, sehingga lulusannya dapat mengembangkan kinerja apabila terjun dalam dunia kerja, memiliki peran yang sangat penting untuk menyiapkan siswanya agar siap bekerja, baik secara mandiri (wiraswasta) maupun mengisi lowongan kerja yang ada. Tenaga kerja yang dibutuhkan adalah sumber daya manusia yang memiliki kompetensi sesuai dengan bidang pekerjaannya, memiliki daya adaptasi dan daya saing yang tinggi.

Kurikulum SMK tahun 2004 dalam proses pembelajaran dibagi dalam tiga diklat, yaitu program normatif, program adaptif, dan program produktif. Dari ketiga program tersebut, program produktif memiliki durasi pembelajaran yang cukup banyak dan menekankan pada pembelajaran praktik. jurusan busana $65-68 \%$ terdiri dari mata pelajaran praktik, dengan harapan agar peserta didik memperoleh pemahaman yang lebih luas dan mendalam terhadap suatu konsep, serta terampil dalam menghasilkan suatu produk busana.

Kompetensi Program keahlian busana adalah membekali peserta didik dengan ketrampilan, pengetahuan, dan sikap agar kompeten dalam hal: )mengukur, membuat pola, menjahit dan penyelesain busana 2 , memilih bahan tekstil dan bahan pembantu secara tepat, 3. menggambar macam-macam busana sesuai kesempatan, 4 . menghias busana sesuai desain busana dan, 5 . mengelola usaha bidang busana.

Kelancaran praktik busana diperlukan adanya ruang praktik yang memadai dilengkapi dengan prasarana, sarana serta pengelolaan yang baik. SMK selayaknya 
memiliki ruang praktik busana yang memiliki standar prasarana, dan sarana yang memenuhi standar nasional sesuai dengan Permendiknas No 40 tahun 2008.

Kenyataan di lapangan sarana dan prasarana praktik di SMK banyak yang tidak sesuai dengan standar, seperti yang diungkap Ketua Umum Asosiasi Pendidikan dan Kejuruan Indonesia (Aptekindo) bahwa ketersediaan sarana dan prasarana atau alat-alat praktik kerja dan bahan-bahan di SMK-SMk sebagian besar masih memprihatinkan. Hanya sedikit SMK yang memiliki fasilitas kerja yang memenuhi kualitas standar, alat praktik yang terbatas dan kuno, prasarana yang rusak, dan pegelolaan laboratorium yang kurang baik sehingga menyulitkan tujuan penyelenggaraan pendidikan kejuruan untuk melahirkan lulusan yang kompeten di bidangnya masing-masing.

Selama ini belum ada penelitian yang telah mengungkap kualitas pengelolaan ruang praktik busana sehingga perlu melakukan penelitian tentang kualitas perencanaan, pengelolaan dan pengawasan ruang praktik busana SMK di Provinsi Bali.

Tujuan dari penelitian ini adalah: (1) Mendiskripsikan kualitas perencanaan ruang praktik busana SMK di Provinsi Bali untuk meningkatkan pelajaran program produktif, (2) Mendiskripsikan kualitas pengorganisasian ruang praktik busana SMK di Provinsi Bali untuk meningkatkan pelajaran program produktif, (3) Mendiskripsikan kualitas pengawasan ruang praktik busana SMK di Provinsi Bali untuk meningkatkan pelajaran program produktif.

\section{METODE}

Rancangan penelitian yang digunakan dalam penelitian ini adalah deskriptif kuantitatif, karena data yang diperoleh dari penelitiaan ini berupa angka-angka. Penelitian yang bertujuan untuk menggambarkan fakta di lapangan mengenai kualitas perencanaan, pengorganisasian, dan pengawasan ruang praktik busana SMK di Propinsi Bali. 
Penelitian ini dilaksanakan pada SMK yang ada di Propinsi Bali. Populasi dalam penelitian ini adalah SMK yang memiliki Program Keahlian Tata Busana di Propinsi Bali. SMK yang ada Program Keahlian Tata Busana di Propinsi Bali terdiri dari 6 SMK, 1 SMK Swasta, dan 5 SMK Negeri. Adapun SMK tersebut adalah, SMK Negeri terdiri dari SMK Negeri 2 Singaraja, SMK Negeri 1 Seririt, SMK 3 Denpasar, SMK 4 Denpasar, SMK 2 Sukawati, dan SMK swasta adalah SMK Marsudirini Negara. Sampel dari penelitian ini adalah guru dan siswa kelas $\mathrm{X}$ program Keahlian Tata Busana. Jumlah guru SMK program keahlian busana yang ada di Propinsi Bali sebanyak 30 Orang. Sedangkan Jumlah Siswa kelas X program keahlian busana sebanyak 111 orang.

Instrumen yang digunakan dalam penelitian ini adalah lembar observasi dan dokumentasi. Lembar observasi pemenuhan kualitas perencanaan, pengorganisasian dan pengawasan ruang praktik busana. Penelitian ini menggunakan metode dokumentasi melalui observasi sebagai data sekunder. Data ini memberian gambaran tentang kualitas perencanaan, pengorganisasian dan pengawasan ruang praktik busana pada saat sekarang. Data yang terkumpul dalam penelitian ini berupa kualitas perencanaan, pengorganisasian, dan pengawasan ruang praktik busana SMK yang ada di Provinsi Bali.

Data yang diperoleh di lapangan diklasifikasikan dan disajikan dalam bentuk tabel, kemudian dianalisis berdasarkan nilai tendensi sentral rerata (mean) skor, dan standar deviasi masing-masing item. Perhitungan analisis data menggunakan bantuan komputer program aplikasi SPSS versi 17,0. Perolehan nilai tendensi sentral rerata (mean) dari setiap item, menggunakan rerata ideal sebagai norma pembanding untuk menentukan kategori. Untuk menghitung besarnya rerata ideal (Mi) dan simpangan baku ideal ( $\mathrm{SDi}$ ), digunakan rumus: $\mathrm{Mi}=1 / 2$ (nilai ideal tertinggi + nilai ideal terendah), dan SDi $=1 / 6$ (nilai ideal tertinggi - nilai ideal terendah). Kualitas prasarana ruang praktik busana, kualitas sarana ruang praktik busana dan pengelolaan ruang praktik busana dikategorikan dengan pedoman sebagai berikut:

$$
\mathrm{Mi}+1,5 \mathrm{SDi} \leq \mathrm{X}<\mathrm{Mi}+3 \mathrm{SDi}=\text { Sangat Baik }
$$

JPTK, UNDIKSHA, Vol. 9, No. 2, Juli 2012 : 61 - 70 


$$
\begin{aligned}
& \mathrm{Mi}+0,5 \mathrm{SDi} \leq \mathrm{X}<\mathrm{Mi}+1.5 \mathrm{SDi} \quad=\text { Baik } \\
& \mathrm{Mi}-0,5 \mathrm{SDi} \leq \mathrm{X}<\mathrm{Mi}+0.5 \mathrm{SDi} \quad=\text { Cukup Baik } \\
& \mathrm{Mi}-1,5 \mathrm{SDi} \leq \mathrm{X}<\mathrm{Mi}-0.5 \mathrm{SDi}=\text { Kurang Baik } \\
& \mathrm{Mi}-3 \mathrm{SDi} \leq \mathrm{X}<\mathrm{Mi}+1.5 \mathrm{SDi}=\text { Sangat Kurang Baik }
\end{aligned}
$$

\section{HASIL DAN PEMBAHASAN}

\subsection{Kualitas Perencanaan Ruang Praktik Busana SMK di Provinsi Bali untuk Meninkatkan Pelajaran Program Produktif}

Data Perencanaan Ruang Praktik Busana SMK di Provinsi Bali diperoleh dari hasil pengukuran terhadap responden guru dan siswa. Dari data diperoleh skor guru menunjukkan skor tertinggi yang dicapai responden adalah 6 dari skor tertinggi yang mungkin dicapai yaitu 6. Sedangkan skor terendah yang dicapai responden adalah 2 dari skor terendah yang mungkin dicapai yaitu 0. Sedangkan dari data skor siswa menunjukkan skor tertinggi yang dicapai responden adalah 6 dari skor tertinggi yang mungkin dicapai yaitu 6. Sedangkan skor terendah yang dicapai responden adalah 6 dari skor terendah yang mungkin dicapai yaitu 0 . Rangkuman hasil observasi kualitas perencanaan ruang praktik busana SMK di Provinsi Bali dapat dilihat pada Tabel 1.

Tabel 1 Rangkuman Hasil Observasi Kualitas Perencanaan Ruang Praktik Busana SMK Di Provinsi Bali

\begin{tabular}{ccccc}
\hline Responden & $\begin{array}{c}\text { Skor } \\
\text { minimum- } \\
\text { maksimum }\end{array}$ & Mean & $\begin{array}{c}\text { Standar } \\
\text { Deviasi }\end{array}$ & Kategori \\
\hline Guru & $2-6$ & 5,40 & 1,28 & Sangat Baik \\
\hline Siswa & $2-6$ & 5,40 & 0,88 & Sangat Baik \\
\hline
\end{tabular}


Secara umum rata-rata skor kualitas perencanaan ruang praktik busana SMK di Propinsi Bali diperoleh dari skor guru yaitu sebesar 5,40 dengan simpangan baku (standar deviasi) sebesar 1,28. Hasil ini menunjukkan bahwa kualitas perencanaan ruang praktik busana SMK di Provinsi Bali dapat dikatakan sangat baik yakni berada pada rentangan 13,50 sampai dengan 18,00 dari skor ideal. Sedangkan dari skor siswa kualitas perencanaan ruang praktik busana SMK di Propinsi Bali didapatkan rata-rata sebesar 5,40 dengan simpangan baku (standar deviasi) sebesar 0,88. Hasil ini menunjukkan bahwa kualitas perencanaan ruang praktik busana SMK di Provinsi Bali untuk meningkatkan pelajaran program produktif dapat dikatakan sangat baik.

\subsection{Kualitas Pengorganisasian Ruang Praktik Busana SMK di Provinsi Bali untuk Meningkatkan Pelajaran Program Produktif}

Data Perencanaan Ruang Praktik Busana SMK di Provinsi Bali diperoleh dari hasil pengukuran terhadap responden guru dan siswa. Dari data diperoleh skor guru menunjukkan skor tertinggi yang dicapai responden adalah 8 dari skor tertinggi yang mungkin dicapai yaitu 8. Sedangkan skor terendah yang dicapai responden adalah 5 dari skor terendah yang mungkin dicapai yaitu 0. Sedangkan dari data skor siswa menunjukkan skor tertinggi yang dicapai responden adalah 8 dari skor tertinggi yang mungkin dicapai yaitu 8. Sedangkan skor terendah yang dicapai responden adalah 3 dari skor terendah yang mungkin dicapai yaitu 0 . Rangkuman hasil observasi kualitas pengorganisasian ruang praktik busana SMK di Provinsi Bali dapat dilihat pada Tabel 2.

Tabel 2 Rangkuman Hasil Observasi Kualitas Pengorganisasian Ruang Praktik Busana SMK Di Provinsi Bali

\begin{tabular}{ccccc}
\hline Responden & $\begin{array}{c}\text { Skor } \\
\text { minimum- } \\
\text { maksimum }\end{array}$ & Mean & $\begin{array}{c}\text { Standar } \\
\text { Deviasi }\end{array}$ & Kategori \\
\hline Guru & $5-8$ & 6,97 & 1,26 & Sangat Baik \\
\hline Siswa & $3-8$ & 6,68 & 1,48 & Sangat Baik \\
\hline
\end{tabular}


Secara umum rata-rata skor kualitas pengorganisasian ruang praktik busana SMK di Provinsi Bali diperoleh dari skor guru yaitu sebesar 6,97 dengan simpangan baku (standar deviasi) sebesar 1,26. Hasil ini menunjukkan bahwa kualitas pengorganisasian ruang praktik busana SMK di Provinsi Bali dapat dikatakan sangat baik. Sedangkan dari skor siswa kualitas pengorganisasian ruang praktik busana SMK di Propinsi Bali didapatkan rata-rata sebesar 6,68 dengan simpangan baku (standar deviasi) sebesar 1,48. Hasil ini menunjukkan bahwa kualitas pengorganisasian ruang praktik busana SMK di Provinsi Bali untuk meningkatkan pelajaran program produktif dapat dikatakan sangat baik.

\subsection{Kualitas Pengawasan Ruang Praktik Busana SMK di Provinsi Bali untuk Meningkatkan Pelajaran Program Produktif}

Data Pengawasan Ruang Praktik Busana SMK di Provinsi Bali diperoleh dari hasil pengukuran terhadap responden guru dan siswa. Dari data diperoleh skor guru menunjukkan skor tertinggi yang dicapai responden adalah 5 dari skor tertinggi yang mungkin dicapai yaitu 5. Sedangkan skor terendah yang dicapai responden adalah 1 dari skor terendah yang mungkin dicapai yaitu 0. Sedangkan dari data skor siswa menunjukkan skor tertinggi yang dicapai responden adalah 5 dari skor tertinggi yang mungkin dicapai yaitu 5. Sedangkan skor terendah yang dicapai responden adalah 0 dari skor terendah yang mungkin dicapai yaitu 0 . Rangkuman hasil observasi kualitas pengawasan ruang praktik busana SMK di Provinsi Bali dapat dilihat pada Tabel 3.

Tabel 3 Rangkuman Hasil Observasi Kualitas Pengawasan Ruang Praktik Busana SMK Di Provinsi Bali

\begin{tabular}{ccccc}
\hline Responden & $\begin{array}{c}\text { Skor } \\
\text { minimum- } \\
\text { maksimum }\end{array}$ & Mean & $\begin{array}{c}\text { Standar } \\
\text { Deviasi }\end{array}$ & Kategori \\
\hline Guru & $1-5$ & 4,43 & 1,17 & Sangat Baik \\
\hline Siswa & $0-5$ & 4,13 & 1,21 & Sangat Baik \\
\hline
\end{tabular}


Secara umum rata-rata skor kualitas pengawasan ruang praktik busana SMK di Provinsi Bali diperoleh dari skor guru yaitu sebesar 4,43 dengan simpangan baku (standar deviasi) sebesar 1,17. Hasil ini menunjukkan bahwa kualitas pengawasan ruang praktik busana SMK di Provinsi Bali dapat dikatakan sangat baik. Sedangkan dari skor siswa kualitas pengawasan ruang praktik busana SMK di Propinsi Bali didapatkan rata-rata sebesar 4,13 dengan simpangan baku (standar deviasi) sebesar 1,21. Hasil ini menunjukkan bahwa kualitas pengawasan ruang praktik busana SMK di Provinsi Bali untuk meningkatkan pelajaran program produktif dapat dikatakan sangat baik.

\subsection{Pembahasan Kualitas Perencanaan, Pengorganisasian dan Pengawasan Ruang Praktik Busana SMK di Propinsi Bali untuk Meningkatkan Pelajaran Program Produktif}

Ruang praktik yang baik adalah ruang praktik yang pengelolaannya didukung dengan manajemen ruang praktik yang benar (Daryanto, 2007). Mulyasa (dalam Bintang, 1998) mendefinisikan manajemen sarana prasarana pendidikan bertugas mengatur dan menjaga sarana prasarana pendidikan agar dapat memberikan kontribusi secara optimal dan berarti pada jalannya proses pendidikan. Kegiatan pengelolaan ini meliputi kegiatan perencanaan, pengadaan, pengawasan, penyimpanan, dan penataan. Manajemen yang baik diharapkan dapat menciptakan sekolah yang bersih, rapi, dan indah sehingga menciptakan kondisi yang menyenangkan baik bagi guru maupun murid untuk berada di sekolah.

Hasil penelitian Sukardi (2008) pengadaan bahan direncanakan oleh guru dan jenisnya sesuai dengan standar, untuk persiapan maupun distribusi bahan dilakukan oleh teknisi dan guru, dan bon bahan dilakukan secara tercatat. Tugas pokok yang harus dilakukan teknisi adalah, mempersiapkan bahan praktik, melayani bon bahan, membantu guru, melayani peminjaman alat, melayani fasilitas untuk kegiatan maintenance, bertanggung jawab terhadap alat/mesin, dan mengecek kelayakan alat/mesin. Pelaksanaan perawatan berprinsip "maintenance berbasis siswa", terencana dan terjadwal. Sedangkan penelitian oleh Raraswati (2010) mengatakan bahwa: (1) perencanaan ruang praktik dilaksankan pada saat 
penyususnan program ruang praktik pada setiap awal tahun ajaran baru, (2) pengorganisasian ruang praktik menggambarkan tentang kedudukan atau wewenang secara hirarki dari setiap unit kerja, dan deskripsi tugas pokok dan fungsi masingmasing jabatan, dan (3) pengawasan pembelajaran dilakukan secara langsung dan tidak langsung, pengawasan langsung dilakukan oleh guru sedangkan pengawasan tidak langsung dilakukan oleh waka kurikulum.

Daryanto (2007) juga menjelaskan bahwa dalam pengelolaan yang baik akan tercipta kondisi ruang praktik yang diharapkan, meliputi: (a) suasana nyaman, bersih, tertib, dan indah; (b) kondisi perakitan yang baik dan siap pakai; (c) peralatan tersusun sesuai tempatnya; (d) cukup penerangan dan ventilasi; (e) instalasi listrik yang memadai dan aman; (f) sistem sirkulasi yang aman dan lancar; (g) instalasi air terjamin, lancar, bersih, dan sehat; dan (h) tersedianya alat pemadam kebakaran. Guna menciptakan kondisi ruang praktik yang diharapkan maka diperlukan perangkat pengelolaan ruang praktik, meliputi: (a) organisasi ruang praktik yang meliputi struktur, uraian kerja, dan tata kerja; (b) tata tertib pengoperasian ruang praktik; (c) jadwal pemakaian ruang praktik (d) sistem pemakaian dan pemeliharaan; dan (e) administrasi ruang praktik.

\section{PENUTUP}

Berdasarkan hasil penelitian dan pembahasan, maka pada penelitian ini dapat disimpulkan hal-hal sebagai berikut:

1. Kualitas perencanaan ruang praktik busana SMK di Provinsi Bali untuk meningkatkan pelajaran program produktif adalah sangat baik. Hal ini ditunjukkan oleh skor guru tentang kualitas perencanaan ruang praktik busana dengan mean 5,40 dari skor ideal 6,00 dan standar deviasi 1,28 sehingga termasuk kategori sangat baik. Sementara skor siswa tentang kualitas pengelolaan ruang praktik busana dengan mean 5,40 dari skor ideal 6,00 dan standar deviasi 0,88 sehingga termasuk kategori sangat baik. 
2. Kualitas pengorganisasian ruang praktik busana SMK di Provinsi Bali untuk meningkatakan pelajaran program produktif adalah sangat baik. Hal ini ditunjukkan oleh skor guru tentang kualitas pengorganisasian ruang praktik busana dengan mean 6,97 dari skor ideal 8,00 dan standar deviasi 1,26 sehingga termasuk kategori sangat baik. Sementara skor siswa tentang kualitas pengorganisasian ruang praktik busana dengan mean 6,68 dari skor ideal 8,00 dan standar deviasi 1,48 sehingga termasuk kategori sangat baik.

3. Kualitas pengawasan ruang praktik busana SMK di Provinsi Bali untuk meningkakan pembelajaran program produktif adalah sangat baik. Hal ini ditunjukkan oleh skor guru tentang kualitas pengawasan ruang praktik busana dengan mean 4,43 dari skor ideal 5,00 dan standar deviasi 1,17 sehingga termasuk kategori sangat baik. Sementara skor siswa tentang kualitas pengelolaan ruang praktik busana dengan mean 4,13 dari skor ideal 5,00 dan standar deviasi 1,21 sehingga termasuk kategori sangat baik.

\section{DAFTAR PUSTAKA}

Bintang. S. 1998. Kesesuaian Manajemen Laboratorium Teknologi pada pendidikan teknik FPTK IKIP Medan. Tesis. Tidak diterbitkan. IKIP Malang.

Daryanto. 2007. Keselamatan dan Kesehatan Kerja Bengkel. Jakarta: PT Rineka Cipta.

Permendiknas. 2008. Undang-undang nomor 40 tahun 2008, Tentang Standar Sarana dan Prasarana Sekolah Menengah Kejuruan/Madrasah Aliyah Kejuruan (SMK/MAK). Jakarta:Departemen Pendidikan Nasional.

Raraswati, R. 2010. Manajemen laboratorium Komputer di Madrasah Ibtidaiyah Negeri (MIN) Malang 2. Skripsi. Tidak diterbitkan. Universitas Negeri Malang.

Sukardi. 2008. Pengembangan Model Bengkel Kerja Praktik Sekolah Menengah Kejuruan. Disertasi. Tidak diterbitkan. Yogyakarta: Universitas Negeri Yogyakarta. 